\title{
Secretion systems and membrane-associated structures in rust fungi after high pressure freezing and freeze-fracturing
}

\author{
Gertrude M. KNAUF and Kurt MENDGEN* \\ Universität Konstanz, Fakultät für Biologie, Lehrstuhl für Phytopathologie, 7750 Konstanz, FRG
}

(Received 11-5-1988; accepted 16-9-1988)

\begin{abstract}
Excellent preservation and new structural details can be demonstrated in rust-infected leaf tissue after high pressure freezing and freeze-fracturing. A tubular-vesicular complex was the most remarkable cytoplasmic structure observed in cells of the bean rust fungus Uromyces appendiculatus var. appendiculatus during its establishment in its host Phaseolus vulgaris. In fungal cells undergoing intensive synthesis of wall material, this membranous system extended throughout the cytoplasm; in addition, vesicles were accumulated adjacent to the plasma membrane. Here, membrane-associated configurations were observed which seem to be involved in exo- and/or endocytotic processes. It is assumed that the tubular-vesicular complex belongs to the endomembraneous system of the bean rust fungus and that it involved in the synthesis and secretion of wall material.
\end{abstract}

high pressure freezing — freeze-fracturing — rust fungi - secretion processes - membrane-associated structures

\section{INTRODUCTION}

In order to understand the interaction of rust fungi with their host plants it is very important to preserve the ultrastructure in its native state. This can be better achieved by the use of cryofixation methods than by chemical fixation. Improved ultrastructural preservation after rapid freezing was demonstrated both with fungal mycelium grown in vitro [4, 5, 7-12] and fungal-infected plant tissue $[2,6]$. Fungi such as Venturia inaequalis and Erysiphe graminis f. sp. hordei colonize the epidermal cells of their host, and can be effectively preserved with rapid freezing methods [2, 6]. In contrast, rust fungi colonize the mesophyll, which makes it difficult to preserve them adequately. Many of the published freezing procedures are not applicable to rust infected plant tissue because of the low freezing rates achieved in whole plant tissue. Well fixed plant tissue can be obtained by combining chemical fixation with cryofixation methods, but fixatives and cryoprotectants introduce many artifacts [30]. They are known, for instance, to alter the morphological and physical properties of membranes.

High pressure freezing (HPF) $[20-22,25]$ overcomes these problems. By the application of a hydrostatic pressure of approximately 2100 bar to the sample, the

\footnotetext{
Abbreviations: $\mathrm{EF}=$ exoplasmic face; $\mathrm{HPF}=$ high pressure freez ing; IMP = intramembrane particle; $P F=$ protoplasmic face; TVC = tubular-vesicular complex.

* Correspondence and reprints
}

critical freezing rate is reduced and specimens up to $600 \mu \mathrm{m}$ thick can be frozen.The use of HPF leads to an excellent preservation of both infected plant and fungal tissue, as is demonstrated with the bean rust fungus in this paper. Furthermore, we were able to describe fungal plasma membrane-associated structures which may be involved in exo- and endocytotic processes.

\section{MATERIALS AND METHODS}

Bean plants (Phaseolus vulgaris cv. Fori) were grown in standard soil under a light-dark period of $16 \mathrm{hr} / 8 \mathrm{hr}(8000 \mathrm{lux})$ and corresponding temperatures of $20^{\circ} \mathrm{C} / 18^{\circ} \mathrm{C}$. Fourteen-day old primary leaves were inoculated with freshly collected uredospores of Uromyces appendiculatus (Pers.) Unger var. appendiculatus, isolate SWBR. Eight days after inoculation leaf samples were fixed by high pressure freezing. Prior to freezing, leaf segments were vacuum infiltrated with tap water of room temperature to remove the air from the intercellular space. Samples $\left(1 \mathrm{~mm}^{2}\right)$ were sandwiched with a drop of tap water between 2 gold-support platelets ( $3 \mathrm{~mm}$ diam.) (Balzers, Lichtenstein). The upper platelet was covered with egg lecithin to ensure that it could be removed without destroying the sample. Freezing was carried out with Balzer's HPM $010[20,22]$. The pressure and temperature course was recorred for each experiment to control the freezing conditions. Frozen samples were stored in liquid nitrogen until the freeze-fracturing step.

Fracturing and replication was carried out with a Balzer's BAF 300 freeze-etch device following standard procedures. Etching was performed at $-110^{\circ} \mathrm{C}$ for approximately $1 \mathrm{~min}$. Replicas were cleaned at room temperature in $12 \%$ alcoholic $\mathrm{KOH}$ for $4 \mathrm{hr}, 70 \%$ sulfuric acid for at least $24 \mathrm{hr}$ and $0.25 \mathrm{M}$ chromic acid for $1 \mathrm{hr}$ [23]. The replicas were mounted on pioloform- 
coated copper grids (50 mesh) and examined with a Zeiss EM $10 \mathrm{C}$ electron microscope at $80 \mathrm{kV}$. The terminology according to Branton et al. [1] was used. The shadowing direction is indicated by an arrowhead on each micrograph.

\section{RESULTS}

Eight days after inoculation, infected tissue contained every developmental stage of the fungus from young intercellular hyphae spreading into uninfected host tissue to sporogenous tissue producing mature uredospores.

After freeze-fracturing, the cytoplasm of the fungal cells had a very smooth surface and the organelles could be easily distinguished. In addition to other organelles, a membrane-bound tubular-vesicular complex (TVC) was clearly visible in every type of fungal cell. We found TVCs which were either composed of only a few tubules (Fig. 1a) or which were formed by large and densely coiled complexes of tubules or cisternae (Fig. 1b). It could not be determined whether the TVCs were spherical or more flattened organelles. Associations of TVCs with any other organelles were not obvious. They were randomly distributed and, depending on the plane of fracture, they were found adjacent to nuclei, endoplasmic reticulum or mitochondria.

Only a few groups of small TVCs were distributed in non-vacuolated intercellular hyphae (Fig. 2). The extent of the TVCs found in the sporogenous tissue depended on the stage of development. Similar to the intercellular hyphae, only small groups of the TVCs existed in the basal cells and uredospore initial cells. The sporophores and especially the developing uredospores, both of which arise from the division of the uredospore initial cells, had extensive TVCs throughout the cytoplasm (Fig. 3). After the formation of the prominent wall by the immature uredospores, the spore spines were deposited between the plasmalemma and the wall (Fig. 4). At this stage of development the extent of TVCs decreased and a greater number of lipid bodies was found in the fungal cells. No TVCs were observed in the mature uredospores, which were densely packed with both small and large lipid bodies (Fig. 5). In contrast to the large spherical lipid bodies, the small ones had an irregular fracture pattern.

The fungal plasma membrane fracture faces, EF and PF, showed the typical distribution of intramembrane particles (IMPs), i.e. fewer particles on the EF and many evenly distributed particles on the PF. Various membraneassociated structures were observed at the plasmalemma of the fungal cells which had TVCs aggregated beneath the plasma membrane and vesicles in close contact with the membranes (Fig. 6a). Canal-like structures similar to that of Fig. 6b were found on the PF. The PF frequently displayed depressions which exhibited IMPs, but at a lower density than the bulk of the plasma membrane (Fig. 6c). The EF showed bulges corresponding to the depressions on the PF (Fig. 6d). Some of the larger bulges were crossfractured and seemed to be filled with an amorphous material. Both elevations and invaginations varied in diameter and depth or height. In addition, IMP-free bulges of various size occurred on the PF of the sporogenous tissue (Fig. 7a). IMPs surrounded such blisters either regularly (Fig. 7b) or irregularly (Fig. 7c). When the membranes were locally disrupted, vesicle-like structures which resembled the smooth bulges were seen in the openings (Fig. 7d). The same cells contained irregularly shaped elevations at the PF, which were IMP-free.

\section{DISCUSSION}

We suggest that the described tubular-vesicular structures belong to the endomembrane system of the rust fungus. There is a correlation between the degree of thickening of the fungal cell wall and the extent of the tubularvesicular complexes (TVCs). The intercellular hyphae were characterized by a relatively low number of TVCs. The
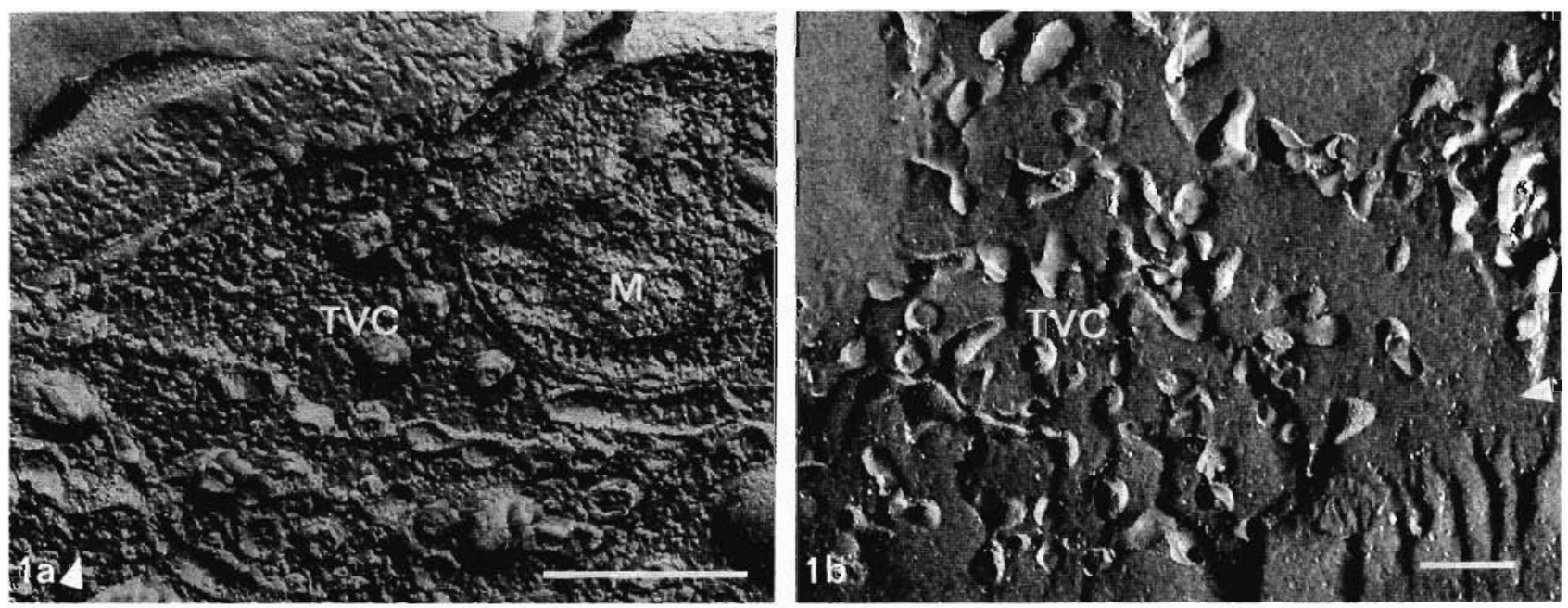

Figure 1. - The TVC may be composed of only a few tubules (a); $\times 69,000$; or they may extend to densely coiled tubules; $\mathbf{M}$ : mitochondrion (b) $\times 30,000$; bars $=0.33 \mu \mathrm{m}$. 

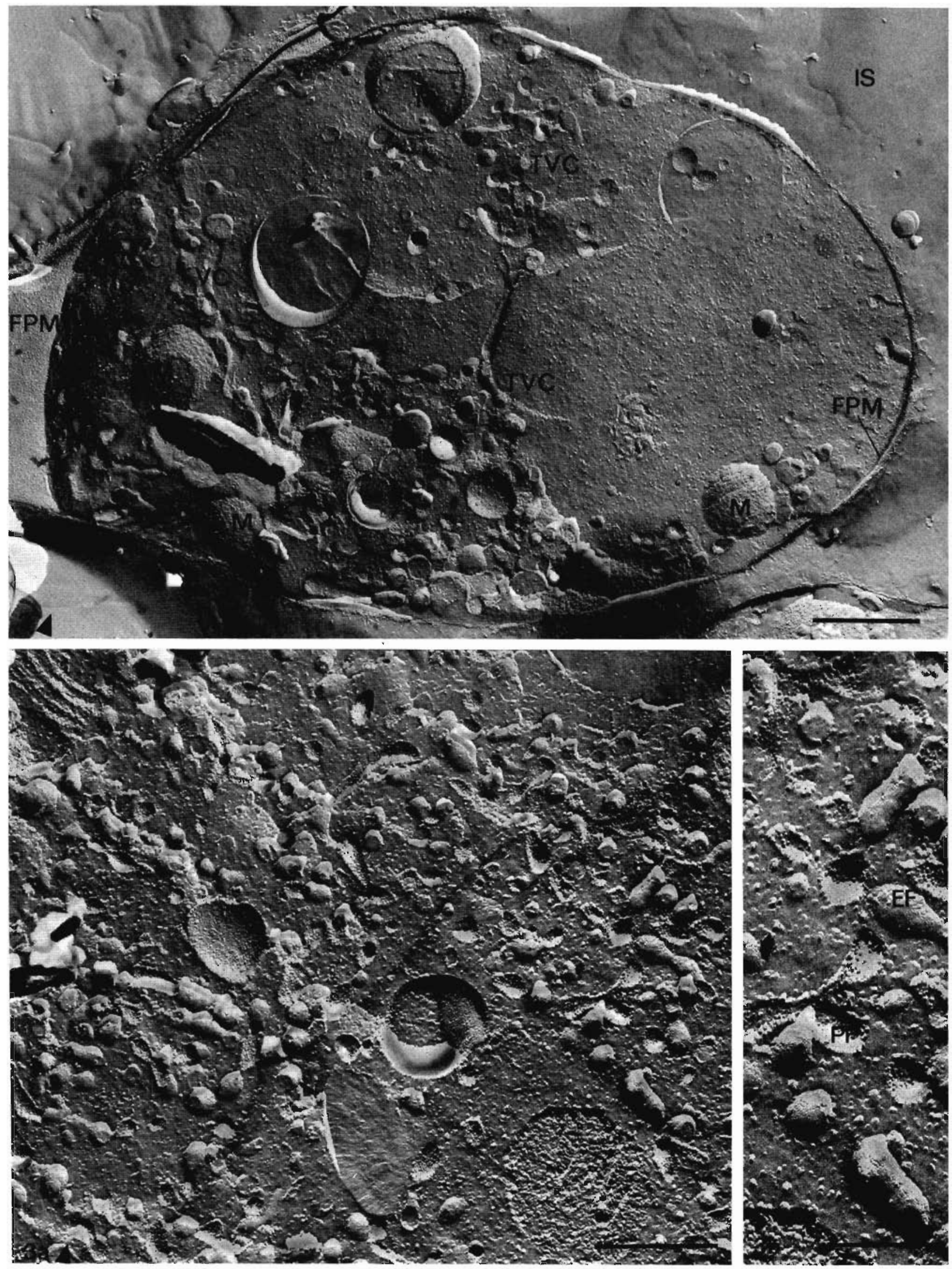

Figure 2. - The intercellular hyphae show only a few tubular-vesicular complexes (TVC). FPM: fungal plasma membrane; IS: intercellular space; $\mathbf{M}$ : mitochondria; $\times 19,000 ;$ bar $=1 \mu \mathrm{m}$.

FIGURE 3. - Sporogenous hyphae exhibit a dense network of TVCs $(\mathbf{a}) ; \times 44,000 ; \mathrm{bar}=0.5 \mu \mathrm{m}$. The EF and PF of the TVCs have a different IMP distribution (b); $\times 80,000 ;$ bar $=0.25 \mu \mathrm{m}$. 

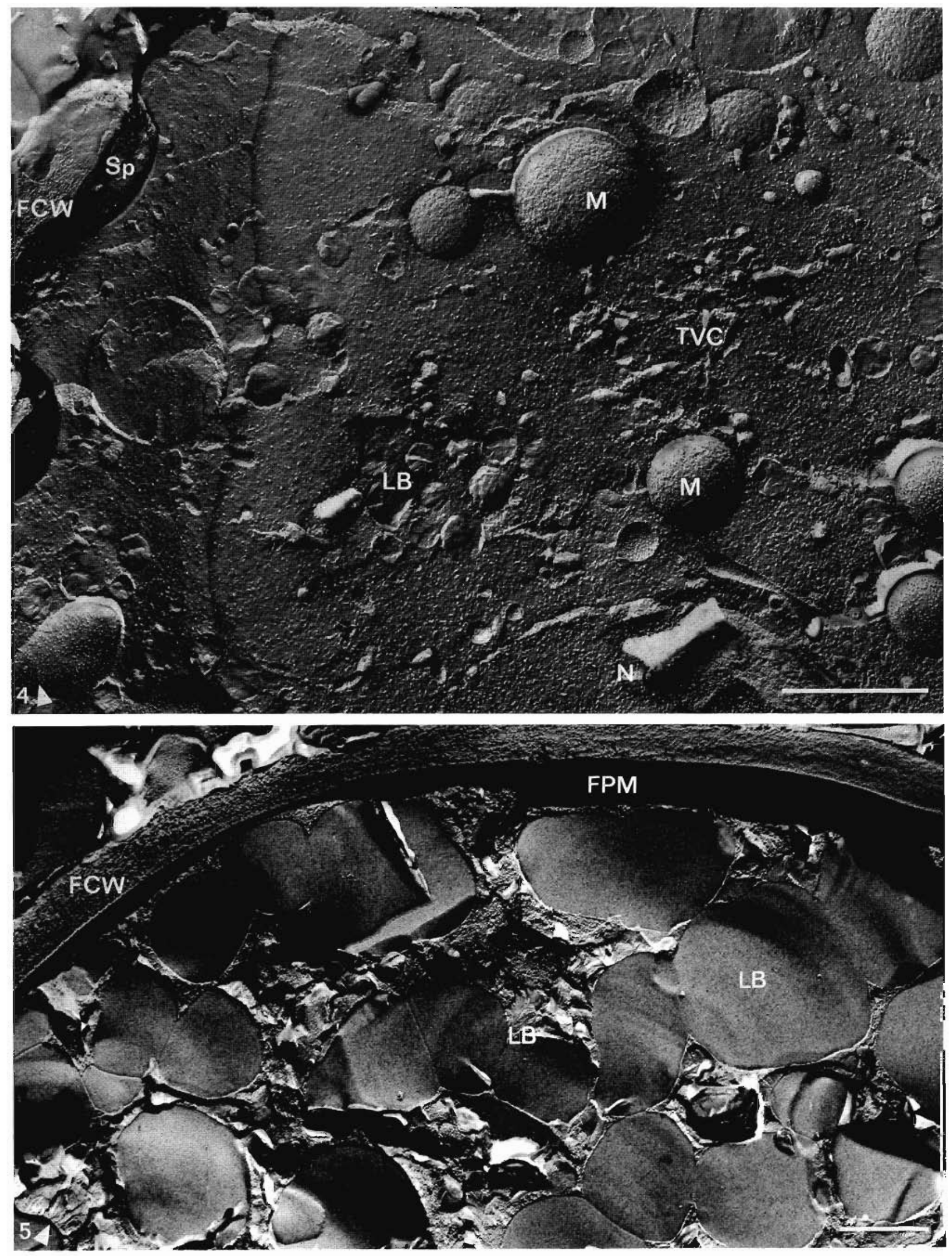

FIGURE 4. - Immature uredospores exhibit, beside mitochondria (M), lipid bodies (LB) and nuclei (N) single TVCs. FCW : fungal cell wall; SP: spore spines; $\times 26,000 ;$ bar $=1 \mu \mathrm{m}$.

FIGURE 5. - The mature uredospores do not exhibit any TVC. The cytoplasm is comprised mainly of lipid bodies (LB) which differ in their fracture pattern. The plasma membrane (FPM) is not undulated and it is closely pressed to the thick fungal wall (FCW); $\times 15,000 ;$ bar $=1 \mu \mathrm{m}$. 

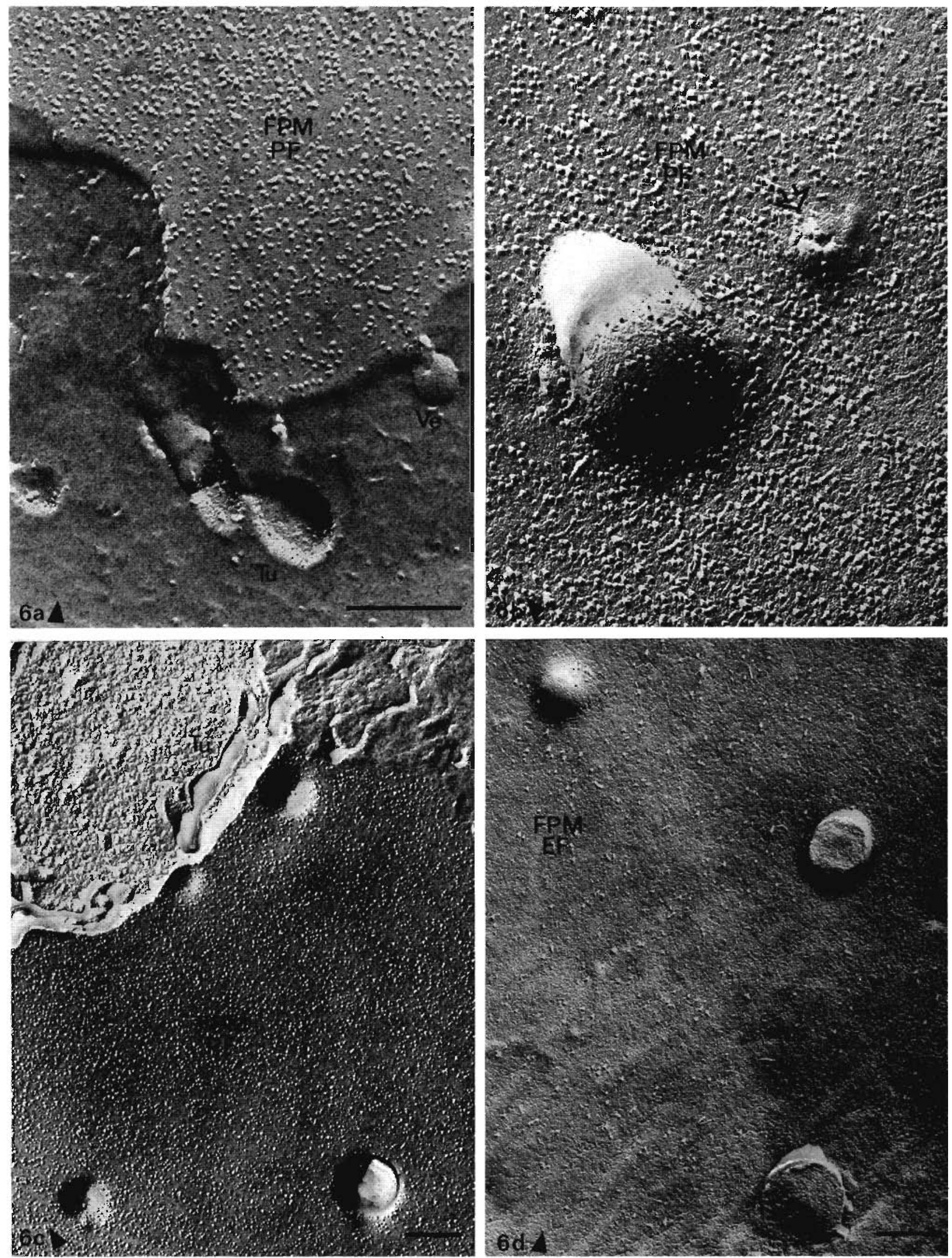

FIGURE 6. - Membranes (FPM) and vesicles (Ve) seem to be connected. Tu: tubule (a); $\times 100,000$. Canal-like holes (open arrow) and elevations which exhibit IMP are rarely found at the PF $(\mathbf{b}) ; \times 101,000$. Depressions of various depth appear at the PF. They showed a few IMPs. Note the tubule (Tu) lying beneath the plasma membrane (FPM) $(\mathbf{c}) ; \times 51,000$. Elevations of various height arise at the EF. In a cross-fracture an amorphous substance appears inside (d); $\times 54,000 ;$ bars $=0.2 \mu \mathrm{m}$. 
situation was very different in the reproductive phase of the fungus. TVCs and individual vesicles were abundant and a dense network of tubular or cisternal structures was produced. Furthermore, membrane-associated structures which could be involved in exocytotic processes [15, 24, 26] were demonstrated at the plasma membranes of the fungal cells. TVCs in the intercellular hyphae may not only be involved in synthesis and secretion of wall material required for the hyphal elongation previously or for the formation of the septae, but they may also serve for the synthesis and secretion of molecules which take part in recognition processes between host and parasite [19]. Sporogenous cells, on the other hand, provide material for the very thick spore walls. This requires considerable synthetic and secretory activity and would explain the extensive TVCs found in these cells.

Similar structures in rust fungi cultivated in vivo have not been described after conventional freeze-fracturing techniques $[3,16]$. Inadequate fixation methods probably caused the deformation of such membranous systems.
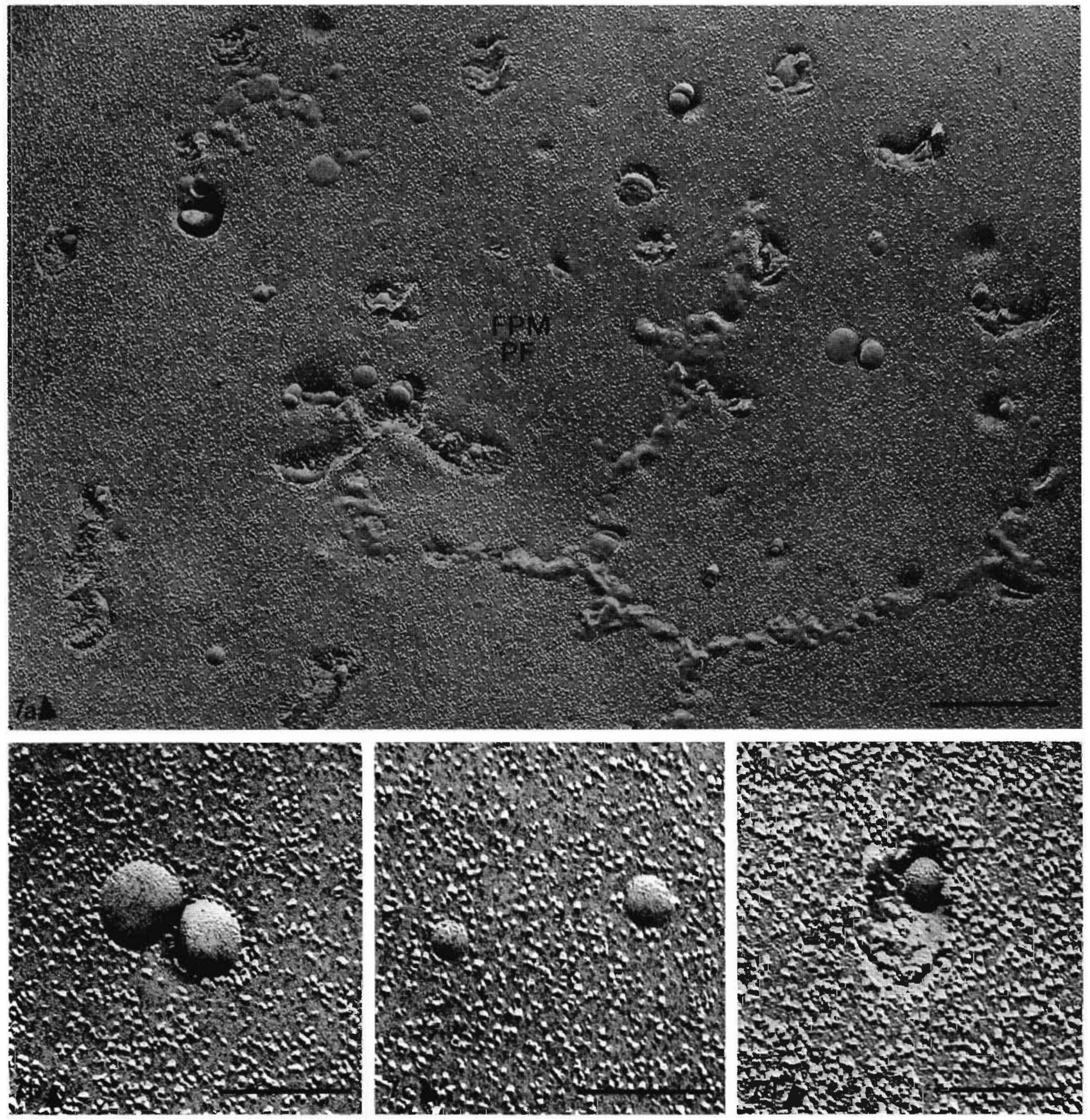

FIGURE 7. - Fungal plasma membranes (FPM) exhibit various membrane structures. Beside small bulges irregularly shaped elevations and depressions appear which are IMP-free (a); $\times 40,000 ;$ bar $=0,5 \mu \mathrm{m}$. Around the bulges the IMP are either regularly (b) or randomly arranged (c). If the membrane is burst similar structures appear in the opening (d); $\times 101,000 ;$ bars $=0.2 \mu \mathrm{m}$. 
Structures resembling the TVCs were also not observed in cryofixed germlings of the bean rust fungus grown in vitro [10]. Although this absence of TVCs could be due to the different preparation techniques, it is more likely that the TVCs are structures specific to the biotrophic phase of the fungus. Up to now, the position of the TVCs in the endomembrane system cannot be determined precisely. Various presumed Golgi systems have been described for fungi [2,5-12], but TVCs are much more complex and larger than the short segments of cisternae or tubules described in those studies. TVCs could represent structures similar to the "grey staining areas" in Erysiphe graminis [2]. It cannot be excluded that the TVC is an aggregation of modified membranes of the endoplasmic reticulum [29]. However, TVC and endoplasmic reticulum could easily be differentiated in our replicas. The latter looked similar to what has been described in other rust fungi after conventional fixation [17].

We suggest that the various membrane-associated structures represent more or less specific intermediate stages of exocytotic processes of the rust fungus. Secretory activity is indicated by a large amount of TVCs. Vesicles connected to the plasma membrane seemed to release their contents out of the protoplast. According to schemes for exocytosis $[15,24,26]$ the canal-like hole of Fig. $6 \mathbf{b}$ may represent an exocytotic canal. It is assumed that exocytotic vesicles give rise to depressions at the PF and corresponding elevations at the EF, which exhibit IMPs. However, it cannot be excluded that the observed membraneintegrated structures are also involved in endocytotic processes, although such processes seem to be unlikely in sporogenous cells. Such membrane-associated structures have never been described in rust fungi. Although the above-described structures may not represent the whole exocytotic process, they should be regarded as a basis for further studies of secretion processes in rust fungi. As a next step we will characterize the content of these vesicles.

We suggest that the structures of Fig. 7 represent membrane regions where vesicular or tubular structures are in such a close contact with the plasma membrane that they cause it to bulge. It cannot be determined whether the cytoplasmic structures are forced against the membrane because of cell dehydration during freezing or whether these structures are involved in membrane dynamic processes. The spore wall is very heterogeneous in composition (chitin, glucans, phenolic compounds) $[13,27,28]$ and it is still unknown whether these various substances are secreted in the same way. Also, it is assumed that material for the spore spines must be secreted and after the spines are formed they must be pushed into the spore wall. We know nothing about the dynamics of these events and further studies are needed to elucidate this question. Furthermore, these structures may be related to specific membrane recycling processes as they are discussed by Staehelin and Chapman [26].

The replacement of chemical pretreatments (which introduce many artifacts) by HPF is a good basis for validity of results. However, care must be taken in the interpretation of the unconventional structures, as there is little information available concerning HPF artifacts. It cannot be excluded that the freezing rate achieved by HPF in deeper regions of the 500- $\mu \mathrm{m}$ thick uredium is insufficient to stabilize membrane dynamic events [20]. The lower freezing rate may also induce phase separation at the plasma membranes, which in turn may induce IMP redistribution [14]. Moreover, pressure-induced alterations may occur at the membranes before they freeze $[18,20]$. Further work is needed to clarify these aspects, as in systems such as rust-infected plant tissue, high pressure freezing is the only available cryofixation method, and it opens up a wide field for further research.

\section{ACKNOWLEDGEMENTS}

Dr. M. Müller from the ETH Zürich provided the high pressure freezing and freeze-fracturing devices. We are also most grateful for his constant and very helpful advice. We thank Prof. $H$. Plattner, Dr. G. Knoll and Dr. S. Craig for discussion of the membrane structures, and Dr. M.A. Stumpf for critically reading the manuscript.

\section{REFERENCES}

1 Branton D.S., Bullivant N.B., Gilula M.J., Karnovsky H., Moor K., Mühletaler D., Northcote H., Packer L., Satir B., Satir P., Speth V., Staehelin L.A., Steere R.L. \& Weinstein R.S. (1975) Freeze-etching nomenclature. Science 190, $54-56$

2 Dahmen H. \& Hobot J.A. (1986) Ultrastructural analysis of Erysiphe graminis haustoria and subcuticular stroma of Venturia inaequalis using cryosubstitution. Protoplasma 131, 92-102

3 Harder D.E. \& Mendgen K. (1982) Filipin-sterol complexes in bean rust- and oat crown rust-fungal/plant interactions : freeze-etch electron microscopy. Protoplasma 112, 46-54

4 Heath I.B., Rethoret K. \& Moens P.B. (1984) The ultrastructure of mitotic spindles from conventionally fixed and freezesubstituted nuclei of the fungus Saprolegnia. Eur. J. Cell Biol. 35, 284-295

5 Heath I.B., Rethoret K., Arsenault A.L. \& Ottensmeyer F.P. (1985) Improved preservation of the form and contents of wall vesicles and the Golgi apparatus in freeze substituted hyphae of Saprolegnia. Protoplasma 128, 81-93

6 Hippe S. (1985) Ultrastructure of haustoria of Erysiphe graminis f. sp. hordei preserved by freeze-substitution. Protoplasma $129,52-61$

7 Hippe S. \& Hermanns M. (1986) Improved structural preservation in freeze-substituted sporidia of Ustilago avenae a comparison with low-temperature embedding. Protoplasma $135,19-30$

8 Hoch H.C. (1986) Freeze-substitution of fungi. In: Ultrastructure Techniques for Microorganisms (H.C. Aldrich and W.J. Todd, eds.), Plenum Publishing Corp., New York, pp. 183-211

9 Hoch H.C. \& Howard R.J. (1980) Ultrastructure of freezesubstituted hyphae of the basidiomycete Laetisaria arvalis. Protoplasma 103, 281-297

10 Hoch H.C. \& Staples R.C. (1983) Ultrastructural organization of the non-differentiated uredospore germling of Uromyces phaseoli var. typica. Mycologia 75, 795-824

11 Howard R.J. (1981) Ultrastructural analysis of hyphal tip cell growth in fungi: spitzenkörper, cytoskeleton and endomembranes after freeze-substitution. J. Cell Sci. 48, 89-103

12 Howard R.J. \& Aist J.R. (1979) Hyphal tip cell ultrastructure of the fungus Fusarium: improved preservation by freeze-substitution. J. Ultrastruct. Res. 66, 224-234

13 Joppien S., Burger A. \& Reisener H.J. (1972) Untersuchungen über den chemischen Aufbau von Sporen- und Keimschlauch-wänden der Uredosporen des Weizenrostes (Puccinia graminis var. tritici). Arch. Mikrobiol. 82, $337-352$

14 Knoll G., Verkleij A.J. \& Plattner H. (1987) Cryofixation of dynamic processes in cells and organelles. In: Cryotechni- 
ques in Biological Electron Microscopy (R.A. Steinbrecht and K. Zierold, eds.), Springer-Verlag, Berlin, pp. 258-271

15 Kroh M. \& Knuiman B. (1985) Exocytosis in nonplasmolyzed and plasmolyzed tobacco pollen tubes. Planta $166,287-299$

16 Littlefield L.J. \& Bracker C.E. (1971) Ultrastructure and development of urediospore ornamentation in Melampsora lini. Can. J. Bot. 49, 2067-2073

17 Littlefield L.J. \& Heath M.C. (1979) Ultrastructure of Rust Fungi. Academic Press, New York

18 MacDonald A.G. (1984) The effects of pressure on the molecular structure and physiological functions of cell membranes. Phil. Trans. R. Soc. Lond. B 304, 47-68

19 Mendgen K., Schneider A., Sterk M. \& Fink W. (1988) The differentiation of infection structures as a result of recognition events between some biotrophic parasites and their hosts. J. Phytopathology 123, 259-272

20 Moor H. (1987) Theory and practice of high pressure freezing. In: Cryofixation in Biological Electron Microscopy (R.A. Steinbrecht and K. Zierold, eds.), Springer-Verlag, Berlin, pp. 175-191

21 Moor H., Bellin G., Sandri C. \& Akert K. (1980) The influence of high pressure freezing on mammalian nerve tissue. Cell Tiss. Res. 209, 201-216

22 Müller M. \& Moor H. (1984) Cryofixation of thick specimens by high pressure freezing. In: Sci. Biol. Spec. Präp., SEM Inc., AMF O'Hare, Chicago, pp. 131-138
23 Platt-Aloia K.A. \& Thomson W.W. (1982) Freeze-fracture of intact plant tissue. Stain Technology 57, 327-334

24 Plattner H. (1981) Membrane behaviour during exocytosis. Cell BIol. Int. Rep. 5, 435-459

25 Riehle U. \& Hoechli M. (1973) The theory and technique of high pressure freezing. In: Freeze-Etching, Techniques and Applications (Benedetti E. and P. Favard, eds.), Société Française de Microscopie Electronique, Paris, pp. $31-61$

26 Staehelin L.A. \& Chapman R.L. (1987) Secretion and membrane recycling in plant cells : novel intermediary structures visualized in ultra-rapidly frozen sycamore and carrot suspension-culture cells. Planta 171, 43-57

27 Trocha P. \& Daly J.M. (1974) Cell walls of germinating uredospores. II. Carbohydrate polymers. Plant Physiol. 53, $527-532$

28 Trocha P., Daly J.M. \& Langenbach R.J. (1974) Cell walls of germinating uredospores. I. Amino acid and carbohydrate constituents. Plant Physiol. 53, 519-526

29 Welter K., Müller M. \& Mendgen K. (1988) The hyphae of Uromyces appendiculatus within the leaf tissue after high pressure freezing and freeze substitution. Prołoplasma 147, $91-99$.

30 Willison J.H.M. \& Brown Jr R.M. (1979) Pretreatment artifacts in plant cells. In: Freeze Fracture: Methods, Artifacts, and Interpretations. (J.E. Rash and C.S. Hudson, eds.), Raven Press, New York, pp. 51-57 